\title{
Existing data sources for clinical epidemiology: Aarhus University Clinical Trial Candidate Database, Denmark
}

This article was published in the following Dove Press journal:

Clinical Epidemiology

8 April 2014

Number of times this article has been viewed

\section{Helene Nørrelund \\ Wiktor Mazin \\ Lars Pedersen}

Department of Clinical Epidemiology, Aarhus University Hospital, Aarhus, Denmark
Correspondence: Helene Nørrelund Department of Clinical Epidemiology, Aarhus University Hospital, Olof Palmes Allé 43, 8200 Aarhus N, Denmark Tel +4587I5 5872

Email hwn@dce.au.dk

\begin{abstract}
Denmark is facing a reduction in clinical trial activity as the pharmaceutical industry has moved trials to low-cost emerging economies. Competitiveness in industry-sponsored clinical research depends on speed, quality, and cost. Because Denmark is widely recognized as a region that generates high quality data, an enhanced ability to attract future trials could be achieved if speed can be improved by taking advantage of the comprehensive national and regional registries. A "single point-of-entry" system has been established to support collaboration between hospitals and industry. When assisting industry in early-stage feasibility assessments, potential trial participants are identified by use of registries to shorten the clinical trial startup times. The Aarhus University Clinical Trial Candidate Database consists of encrypted data from the Danish National Registry of Patients allowing an immediate estimation of the number of patients with a specific discharge diagnosis in each hospital department or outpatient specialist clinic in the Central Denmark Region. The free access to health care, thorough monitoring of patients who are in contact with the health service, completeness of registration at the hospital level, and ability to link all databases are competitive advantages in an increasingly complex clinical trial environment.
\end{abstract}

Keywords: Denmark, single point-of-entry, patient registration

\section{Introduction}

The randomized controlled clinical trial is one of the most powerful tools available to clinical researchers. ${ }^{1}$ Clinical trials seek to improve disease prevention, detection, treatment, and rehabilitation. Their essential purpose is to determine whether a particular intervention, new or established, can reasonably be inferred to cause a change in health. They are often characterized as industry-driven or investigator-driven. Clinical trials sponsored by industry support development of new drugs, devices, and medical practices, with the potential for offering patients and clinicians new evidence-based treatment options. Investigator-driven trials, most often based in academic institutions, also benefit from collaboration with industry, as revenues may stimulate all sorts of research.

The number of industry-sponsored trials is decreasing worldwide, ${ }^{2}$ and reports from the Danish Health and Medicines Authority and Danish Association of the Pharmaceutical Industry reveals a 30\% decline in clinical trial activity in Denmark from 2007 to $2012,3,4$ while the impact of issues impinging on the cost, quality, and speed required to conduct clinical trials is increasing. ${ }^{5}$ A typical source of delay is the ability to successfully recruit, enroll, and retain patients in a trial. Clinical trial sites in Western Europe are not meeting industry expectations or site commitments, with about one-third of sites significantly under-recruiting patients. ${ }^{5}$ Emerging economies 
like India and the People's Republic of China capture more of the market share for clinical trials, with lower overall costs associated with the conduct of clinical trials and faster patient recruitment. ${ }^{5}$ Other significant challenges in many countries are systemic infrastructure issues such as contract and budget negotiation and approval, protocol amendment and refinement, and review and approval of consent forms. ${ }^{5}$ Delays in startup due to slow administrative processes exacerbate problems with patient recruitment, because the first patient cannot be recruited until all necessary approvals are in place. This narrows the window of opportunity to recruit the full number of patients projected at a specific site. Sites that obtain all needed approvals sooner are able to enroll more patients in global studies and these problems can be solved by ensuring an efficient administrative infrastructure for clinical trials. The longer-term effect of more rapid enrollment is an enhanced ability to attract future trials, because increased enrollment capacity reduces the cost to industry.

Some countries have managed to develop clear and focused clinical trial strategies to increase their market share. In 2012, the Ministry of Health and Labor Welfare in Japan announced its third action plan for boosting efficiency, cost optimization, staff training, and patient education to encourage more clinical research in Japan. ${ }^{5}$ Integration of modern information technology to track cases and improve information storage is a major component of the plan. Some European countries have adopted a centralized ethics review model to streamline administrative processes. ${ }^{5}$ In Canada, a $12 \%$ annual loss in global market share has led the provinces to develop strategic plans regarding how to improve and enhance infrastructure to regain position. ${ }^{6}$

In 2012, to reposition Denmark strategically for success in an increasingly competitive global clinical trials market, the Danish regions launched a new initiative, ie, a "single point-of-entry" system (SPOE) for clinical trials. The goal of this initiative is to support collaboration between hospitals and industry. ${ }^{5}$

The SPOE system was conceived to ensure that industry can make contact with a unified health care system. ${ }^{5}$ Companies can use the SPOE system to obtain recommendations regarding potential investigators for clinical trials in all parts of Denmark. Authorities in the five Danish regions collaborate across regional borders and are therefore in a position to provide comprehensive feedback on potential Danish centers suitable for a proposed clinical trial.

Every region has appointed a person to coordinate and streamline clinical trial efficiencies. Accordingly, the SPOE system is in continuous dialogue with clinicians in the different hospital departments, the Danish Contract Research Organizations, the Danish Pharmaceutical Industry, Dansk Biotek, an industry association of Danish companies, and Danish regions to optimize clinical trial infrastructure.

The SPOE system acts as a gateway for industry to make contact with appropriate clinical centers, assisting industry in early-stage feasibility assessments by identifying candidate investigators for specific clinical trials. Potential trial participants can be identified by use of registries. About 50 enquiries from commercial companies were fielded in 2013.

In addition, the SPOE system supports the creation of clinical trial units and fosters closer collaboration between relevant partners in clinical research. ${ }^{5}$ It thus assists in building a coordinated network of clinical trial capacity. The SPOE system also plays a crucial role in creating an effective support structure to ease the administrative burden on investigators (eg, supporting broad dissemination of best practices in contracts and standard operating procedures). Via the SPOE system, the five regions collaborate closely on harmonizing administrative processes and platforms.

\section{Structure and organization of the Danish health care system}

Denmark's population is homogenous with regard to access to health care and basic education because its taxsupported welfare system guarantees the entire population (5.6 million people) free health care and education at the point of delivery. ${ }^{7}$ In Denmark, general practitioners serve as gatekeepers to the broader health care system by providing referrals to hospitals and specialists. ${ }^{7}$ Traditionally, Danish hospitals and primary health services have been administered by the regions, while responsibility for optimizing conditions that govern clinical research is shared by the four Danish faculties of health sciences.

All citizens have a personal civil registration (CPR) number assigned at birth or upon immigration. ${ }^{8}$ The CPR number serves as a unique identifier and allows access to individual-level information stored in administrative and health-related databases. A county-based hospital registration system set up in the 1970s to collect information on the activities of hospitals ${ }^{9}$ formed the basis of the Danish National Registry of Patients (DNRP) in 1977, when the National Board of Health requested that the counties provide data from public hospitals. Inpatient hospitalizations have been recorded in the DNRP since 1977, and all outpatient specialist visits and emergency room contacts have been included since 1995. Currently, the DNRP contains information on all admissions and outpatient visits to Danish hospitals. For each 
hospital admission, the DNRP records dates of admission and discharge, surgical procedures performed, and up to 20 diagnoses classified according to the International Classification of Diseases, Tenth Revision. ${ }^{8,10}$ All regions (until 2007, counties) store information in the Patient Administrative System (PAS).${ }^{11}$ Because the PAS for each region collects data for the DNRP, there is considerable overlap between the information accessible in the two registries. The Aarhus University Clinical Trial Candidate Database is based on encrypted PAS data from Central Denmark Region.

By referring to Denmark as a cohort, ${ }^{12}$ Lone Frank drew attention to the fact that Denmark possesses a wealth of individual-level data. Free access to health care, completeness of registration at the hospital level, and ability to link all databases using the CPR number make it possible to follow each Dane longitudinally from birth to death. Use of the CPR number also makes it possible to link laboratory data ${ }^{13}$ to a wide range of Danish registries, including the DNRP, the Danish civil registration system (which contains exact dates of immigration, emigration, and death), and the prescription database. ${ }^{14}$ This comprehensive ability to collect data is an invaluable tool in clinical research.

\section{Recruitment linked to the Danish National Registry of Patients}

Denmark has a tradition of thorough monitoring of patients who use the health service. Some databases were established as early as the $1920 \mathrm{~s} .{ }^{15}$ In recent decades, computerized patient registration systems have allowed integrated collection of data and tracking the number of visits and diagnoses in general practices, at private specialist clinics, and at public hospitals.

Access to a reliable source of unselected patients is particularly valuable in clinical research and constitutes a competitive advantage. ${ }^{5}$ Industry sponsors often assess feasibility in several countries at the same time and this global race allows only for the most rapidly recruited respondents to participate in the trial. Up until now, pharmaceutical companies considering clinical trial sites in Denmark have had to administer a feasibility questionnaire to clinicians, requesting that they estimate the number of patients with the relevant diagnosis in their clinics. Response rates have often been disappointing because clinicians are given only a short time frame (typically a few days) to provide the requested information. Furthermore, estimation of numbers of eligible patients has often been overly optimistic, resulting in under-recruitment.

The Aarhus University Clinical Trial Candidate Database (AUCTCD) consists of encrypted data from the PAS/ DNRP. When assisting industry in early-stage feasibility, the SPOE system can make use of the AUCTCD, which allows immediate estimation of numbers of patients (Table 1) with a specific discharge diagnosis in each hospital department or outpatient specialist clinic in the Central Denmark Region (Figure 1). The SPOE coordinator has access to the AUCTCD. The company addresses this coordinator and numbers can be provided immediately. Because the data are encrypted, it is not possible to identify individual patients. Therefore, permission is not needed from the Danish Data Protection Agency, so there is no delay in response. The PAS/ DNRP AUCTCD can provide the number of patients (identified by their CPR numbers) who have been treated in a given hospital department or outpatient clinic during the previous year. Figure 2 illustrates how patients can be mapped in the Central Denmark Region according to a specific diagnosis.

Companies typically contact the SPOE system with a potential new treatment for a specific disease in order to identify patients for Phase III testing. Encrypted data from the PAS/DNRP AUCTCD allows immediate determination of the number of relevant patients seen in the hospitals and clinics during the previous year. Based on these numbers, potential investigators are contacted to assess local clinical trial capacity and, when appropriate, to establish a recruitment site. Mapping of patients in the entire Central Denmark Region promotes collaboration between departments and leads to increased enrollment capacity. Figure 2 indicates how patients with such diagnoses as tinnitus and lymphocytic colitis are easily identified at departments of otorhinolaryngology and gastroenterology, while patients with spastic paralysis can be found in three different types of departments. The number of relevant departments increases to seven if the objective is to find patients with back pain. To illustrate the type of information available, Table 2 shows examples of numbers of patients with given disease entities by subtype, and these data can be further subdivided by sex and age.

When a potential clinical trial site has been identified by a company on the basis of the number of patients with a specific diagnosis, the local clinician has to complete a feasibility survey by screening medical records and verifying that he or she will be able to recruit the required number of patients. Eventually, if the site is included in the study, patient recruitment is carried out by local doctors without use of registries and according to the regulations of The Danish Research Ethics Committee.

\section{Broader research perspectives}

Phase III randomized clinical trials focus on short-term efficacy and safety in narrow populations with strict inclusion 
Table I Number of patients with specific diagnoses treated at hospitals in the Central Denmark Region in 2012

\begin{tabular}{|c|c|c|c|c|c|}
\hline & $\begin{array}{l}\text { Aarhus University } \\
\text { Hospital }\end{array}$ & $\begin{array}{l}\text { Viborg/Silkeborg } \\
\text { Hospital }\end{array}$ & $\begin{array}{l}\text { Horsens } \\
\text { Hospital }\end{array}$ & $\begin{array}{l}\text { Herning/Holstebro } \\
\text { Hospital }\end{array}$ & $\begin{array}{l}\text { Randers } \\
\text { Hospital }\end{array}$ \\
\hline \multicolumn{6}{|l|}{ Hypertension } \\
\hline Total & 1,917 & 868 & 898 & 742 & 619 \\
\hline New cases & 875 & 550 & 466 & 472 & 427 \\
\hline \multicolumn{6}{|l|}{ Gastric ulcer } \\
\hline Total & 34 & 7 & 14 & 20 & 55 \\
\hline New cases & 27 & 6 & 10 & 12 & 32 \\
\hline \multicolumn{6}{|c|}{ Crohn's disease } \\
\hline Total & 868 & 375 & 238 & 231 & 234 \\
\hline New cases & 109 & 56 & 45 & 56 & 18 \\
\hline \multicolumn{6}{|c|}{ Rheumatoid arthritis } \\
\hline Total & 464 & 1,018 & 289 & 78 & 400 \\
\hline New cases & 95 & 187 & $4 I$ & 16 & 59 \\
\hline \multicolumn{6}{|l|}{ Stroke } \\
\hline Total & 2,260 & 569 & 452 & 1,210 & 614 \\
\hline New cases & 991 & 226 & 143 & 600 & 213 \\
\hline \multicolumn{6}{|c|}{ Acute myocardial infarction } \\
\hline Total & 1,832 & 367 & 379 & 579 & 557 \\
\hline New cases & 617 & 165 & 135 & 249 & 148 \\
\hline \multicolumn{6}{|l|}{ Cirrhosis } \\
\hline Total & 526 & 96 & 116 & 100 & 151 \\
\hline New cases & 122 & 34 & 28 & 33 & 33 \\
\hline \multicolumn{6}{|c|}{ Atrial fibrillation } \\
\hline Total & $1,4 \mid 4$ & 495 & 769 & 592 & 872 \\
\hline New cases & 372 & 190 & 243 & 254 & 285 \\
\hline \multicolumn{6}{|l|}{ Pneumonia } \\
\hline Total & 2,104 & $\mathrm{I}, 326$ & $|| 8 \mid$, & $\mathrm{I}, 60 \mathrm{I}$ & $\mathrm{I}, 745$ \\
\hline New cases & 1,318 & 881 & 641 & $|, 00|$ & 801 \\
\hline \multicolumn{6}{|c|}{ Venous thromboembolism } \\
\hline Total & 520 & 389 & 283 & 471 & 379 \\
\hline New cases & 199 & 172 & 132 & 200 & 140 \\
\hline \multicolumn{6}{|l|}{ Cancer* } \\
\hline Total & 5,761 & 2,555 & 529 & 2,625 & 1,062 \\
\hline New cases & 901 & 678 & 190 & 535 & 501 \\
\hline
\end{tabular}

Notes: Total, total number of patients treated in 2012; new cases, number of new cases in 2012; *pulmonary, breast, colorectal, prostatic cancers.

criteria, whereas post-marketing surveillance is undertaken to gather information on the effect of a drug or other treatment in various populations and any side effects associated with its use. ${ }^{1}$ Access to population-based health care databases may provide additional clinical support by permitting complete lifelong follow-up, as currently occurs in Denmark where event information is automatically collected. ${ }^{16}$

Conducting prospective, randomized, controlled, openlabel clinical trials, with identification of patients and evaluation of endpoints based on high-quality registries, may complement the strengths and address the weaknesses of both randomized clinical trials and comparative observational registry studies. A recent study in Sweden randomized patients with acute myocardial infarction to determine if thrombus aspiration reduced mortality. Patients were enrolled from the national comprehensive Swedish Coronary Angiography and
Angioplasty Registry and national registries were used to collect outcome data. ${ }^{17}$ At the same time, large retrospective epidemiological studies are being carried out using both the diagnostic histological and cytological specimens routinely stored in pathology department archives since $1997^{18}$ and prescription data from the Danish National Database of Reimbursed Prescriptions with information on use of dispensed drugs since $2004 .{ }^{19}$ It is possible to identify patients with a particular medical condition or disease of interest, obtain individual information on dispensed prescriptions, identify the location of archived specimens, and retrieve these specimens for additional analyses. As the Danish National Pathology Registry and the Danish Pathology Data Bank are public registries, access to data can be obtained if the project and investigators in question meet the criteria determined by the Danish Data Protection Agency and the 


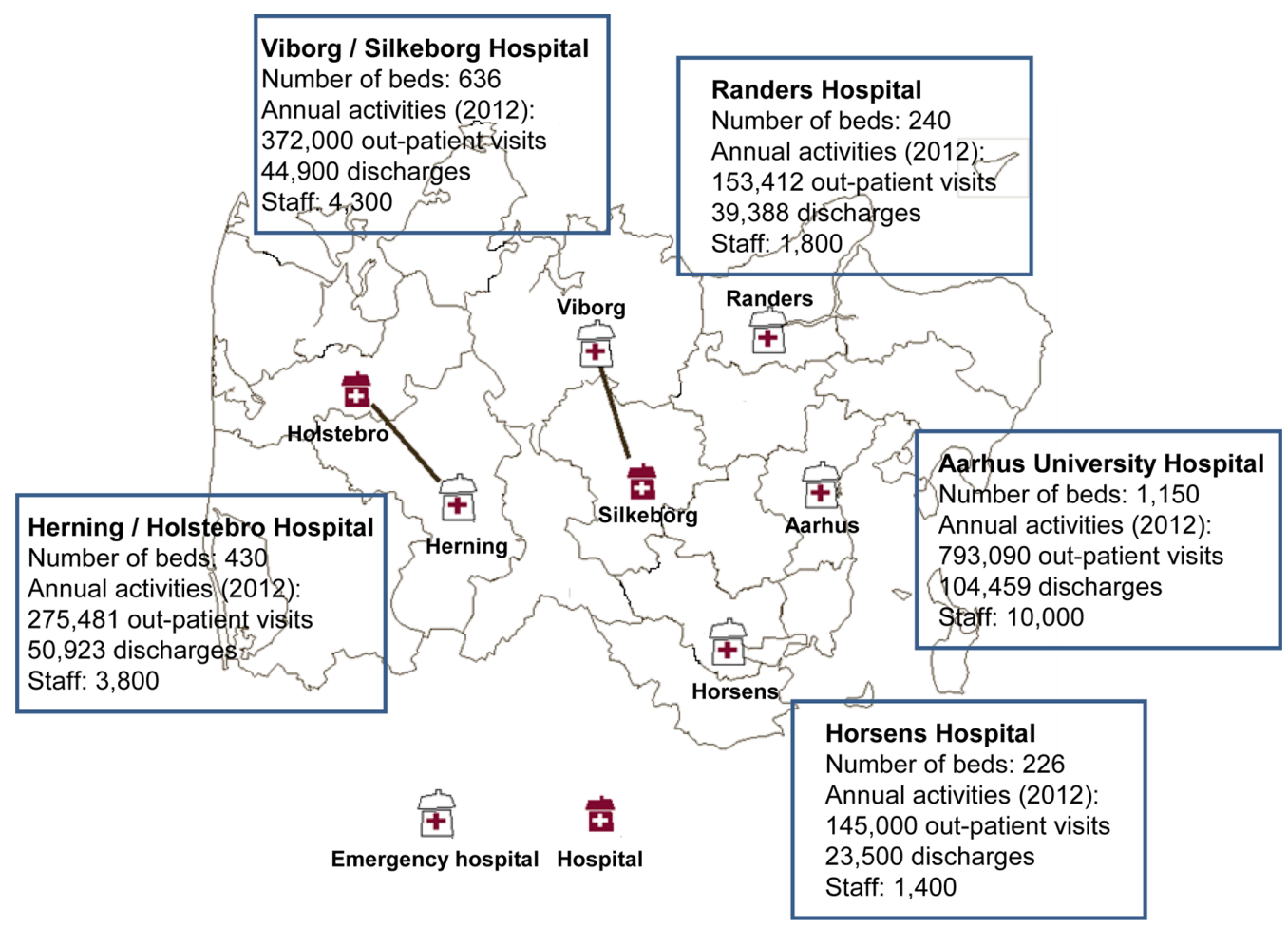

Figure I Hospitals in the Central Denmark Region.

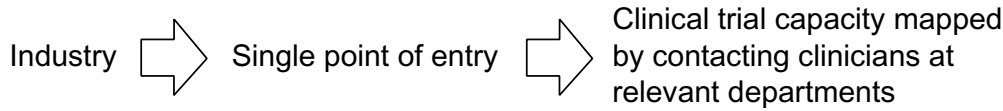
relevant departments

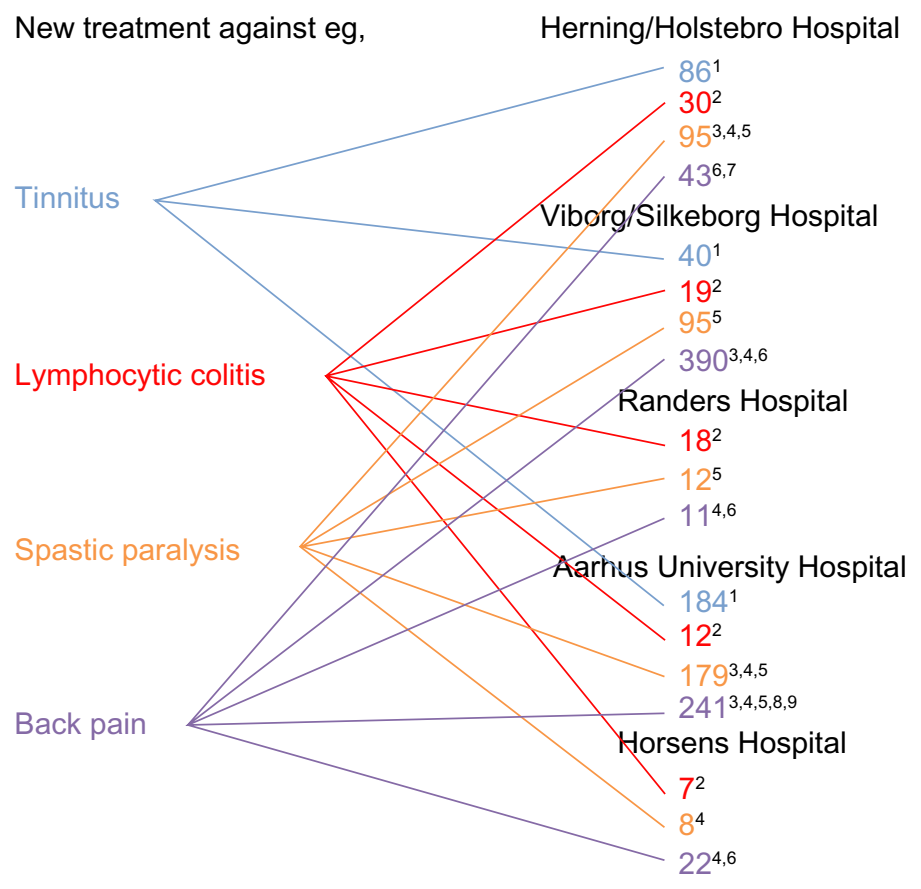

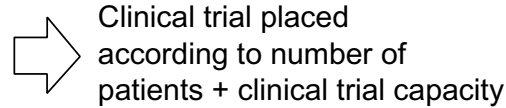

${ }^{1}$ Department of otorhinolaryngology, head and
neck surgery

${ }^{2}$ Department of hepatology and gastroenterology

${ }^{3}$ Department of neurology

${ }^{4}$ Department of orthopaedic surgery

${ }^{5}$ Department of paediatrics

${ }^{6}$ Department of internal medicine

${ }^{7}$ Department of occupational medicine

${ }^{8}$ Department of rheumatology

${ }^{9}$ Department of neurosurgery

Figure 2 Mapping of patients in Central Denmark Region.

Notes: Numbers refer to number of patients in out-patient clinics in 2012; superscript numbers refer to clinical departments. 
Table 2 Examples of numbers of patients by disease entity and subtype

\begin{tabular}{|c|c|}
\hline Diagnosis & $\begin{array}{l}\text { Patients at Aarhus } \\
\text { University Hospital } \\
\text { in } 2012 \text { (n) }\end{array}$ \\
\hline \multicolumn{2}{|l|}{ Gastric ulcer } \\
\hline Corpus ventriculi with bleeding & 21 \\
\hline Corpus ventriculi with perforation & 3 \\
\hline Corpus ventriculi without & 10 \\
\hline \multicolumn{2}{|l|}{ bleeding/perforation } \\
\hline \multicolumn{2}{|l|}{ Crohn's disease } \\
\hline Small bowel & 68 \\
\hline lleum & 1 \\
\hline Colon & 41 \\
\hline Rectum & 2 \\
\hline Other type of Crohn's disease & 74 \\
\hline Both small bowel and colon & 8 \\
\hline Mouth & 1 \\
\hline Not specified & 717 \\
\hline Arthritis & 7 \\
\hline \multicolumn{2}{|l|}{ Rheumatoid arthritis } \\
\hline Not specified & 3 \\
\hline Respiratory involvement & 7 \\
\hline Pleural effusion & I \\
\hline Vasculitis & 4 \\
\hline Other organs & 1 \\
\hline Other type of seropositive & 4 \\
\hline \multicolumn{2}{|l|}{ rheumatoid arthritis } \\
\hline Seropositive without specification & 398 \\
\hline Seronegative rheumatoid arthritis & 46 \\
\hline Other type of rheumatoid arthritis & 2 \\
\hline \multicolumn{2}{|l|}{ Stroke } \\
\hline Infarction & 1,908 \\
\hline Hemorrhage & 354 \\
\hline \multicolumn{2}{|l|}{ Cirrhosis } \\
\hline Alcoholic & 329 \\
\hline Primary biliary & 98 \\
\hline Secondary biliary & 3 \\
\hline Other & 108 \\
\hline Macronodular & 3 \\
\hline Not specified & 21 \\
\hline Cryptogenic & 11 \\
\hline
\end{tabular}

National Board of Health, ${ }^{18}$ and information on how to apply can be found on their homepage (http://www.patobank.dk/). To access biological specimens, additional approval from The Danish Research Ethics Committee is necessary and permission must be sought from each pathology department holding the specimens. ${ }^{18}$ Access to the Danish National Database of Reimbursed Prescriptions can be obtained under the prerequisite that the research protocol has been approved by the chairman of the database and the aforementioned authorities. ${ }^{19}$ The database is established at the Department of Clinical Epidemiology at Aarhus University, so researchers are welcome to contact the department (http://www.kea.au.dk/en/home/).

\section{Quality of data}

Since the DNRP serves as the basis for payments to public hospitals via the Diagnostic Related Group system, the completeness of registration of contacts with the health care system is expected to be high. ${ }^{9}$ The registry has been validated in earlier studies, and data completeness and validity (ie, the extent to which a record of an event corresponds to the event) are continuously monitored., ${ }^{90,20-28}$ The studies show that the validity of the administrative data and the overall data concerning procedures is high, although large differences are seen for specific diagnoses. Consequently, it is recommended that work with selected data is confirmed in another registry or at the primary source.

\section{Conclusion}

Scandinavian health care, disease, and population registries are recognized as being amongst the best in the world due to their large size, long recording period, high quality, and completeness. High quality clinical data linked with access to large biobanks and advanced molecular biological techniques allow identification of novel prognostic and predictive biomarkers in the era of personalized medicine. This advantage can reposition Denmark to be more competitive in an increasingly complex global clinical trials environment. Use of SPOE and health care databases is likely to improve patient recruitment and thereby shorten trial startup times. By increasing the speed of patient recruitment, streamlining processes, and building a coordinated network of clinical trial capacity in partnership with trial sites, Denmark can retain and develop its position as one of the countries with the highest number of clinical trials per capita. This will promote involvement in leadingedge medical research, as well as local access to the most advanced evidence-based care.

\section{Disclosure}

The authors report no conflicts of interest in this work.

\section{References}

1. Gallin JI, Ognibene FP, editors. Principles and Practice of Clinical Research. 3rd ed. Amsterdam, The Netherlands: Academic Press; 2012.

2. http://www.clinicaltrials.gov.

3. Danish Health and Medicines Authority. [Årsrapport 2012. Kliniske forsøg med lægemidler på mennesker.]

4. The Danish Association of the Pharmaceutical Industry and DANSK BIOTEK. Resultater fra Lif og Dansk Bioteks undersøgelse af kliniske forskningsaktiviteter i Danmark 2012.

5. Danish Regions. Én indgang for industrien til kliniske forsøg i Danmark. Strategic plan for increasing Denmark's share of global clinical trials. 2012 
6. Clinical Trials Ontario. Inaugural strategic plan. Making Ontario a preferred location for global clinical trials. 2012-2017 Strategic Plan. Available from: http://www.ctontario.ca/wp-content/uploads/2012/07/ CTO-Strategic-Plan-June-2012.pdf. Accessed March 4, 2014.

7. Ministry of Health and Prevention. Healthcare in Denmark. 2008. Available from: http://www.sum.dk/Aktuelt/Publikationer/ /media/ Filer\%20-\%20Publikationer_i_pdf/2008/UK_Healthcare_in_dk/pdf. ashx. Accessed March 4, 2014.

8. Pedersen CB. The Danish civil registration system. Scand J Public Health. 2011;39 Suppl 7:22-25.

9. Lynge E, Sandegaard JL, Rebolj M. The Danish National Patient Register. Scand J Public Health. 2011;39 Suppl 7:30-33.

10. Andersen TF, Madsen M, Jørgensen J, Mellemkjoer L, Olsen JH. The Danish National Hospital Register. A valuable source of data for modern health sciences. Dan Med Bull. 1999;46:263-268.

11. Sørensen HT, Christensen T, Schlosser HK, Pedersen L, editors. Use of Medical Databases in Clinical Epidemiology. 2nd ed. Aarhus, Denmark: Sun-Tryk, Aarhus University; 2009.

12. Frank L. When an entire country is a cohort. Science. 2000;287: 2398-2399.

13. Grann AF, Erichsen R, Nielsen AG, Frøslev T, Thomsen RW. Existing data sources for clinical epidemiology: the clinical laboratory system (LABKA) research database at Aarhus University, Denmark. Clin Epidemiol. 2011;3:133-138.

14. Kildemoes HW, Sørensen HT, Hallas J. The Danish National Prescription Registry. Scand J Public Health. 2011;39:38-41.

15. Uldall P, Michelsen SI, Topp M, et al. The Danish Cerebral Palsy Registry. A registry on a specific impairment. Dan Med Bull. 2001;48: 161-163

16. Thuesen L, Jensen LO, Tilsted HH, et al. Event detection using population-based health care databases in randomized clinial trials: a novel research tool in interventional cardiology. Clin Epidemiol. 2013;5:357-361.

17. Frøbert O, Lagerqvist B, Olivecrona GK, et al. Thrombus aspiration during ST-segment elevation myocardial infarction. $N$ Engl J Med. 2013;369:1587-1597.
18. Erichsen R, Lash TL, Hamilton-Dutoit SJ, Bjerregaard B, Vyberg M, Pedersen L. Existing data sources for clinical epidemiology: the Danish National Pathology Registry and Data Bank. Clin Epidemiol. 2010;2:51-56

19. Johannesdottir SA, Horváth-Puhó E, Ehrenstein V, Schmidt M, Pedersen L, Sørensen HT. Existing data sources for clinical epidemiology: The Danish National Database of Reimbursed Prescriptions. Clin Epidemiol. 2012;4:303-313.

20. Madsen M, Davidsen M, Rasmussen S, Abildstrom SZ, Osler M. The validity of the diagnosis of acute myocardial infarction in routine statistics: a comparison of mortality and hospital discharge data with the Danish MONICA registry. J Clin Epidemiol. 2003;56:124-130.

21. Thygesen SK, Christiansen CF, Christensen S, Lash TL, Sørensen HT. The predictive value of ICD-10 diagnostic coding used to assess Charlson comorbidity index conditions in the population-based Danish National Registry of Patients. BMC Med Res Methodol. 2011;11:83.

22. Fonager K, Sørensen HT, Rasmussen SN, et al. Assessment of the diagnoses of Crohn's disease and ulcerative colitis in a Danish hospital information system. Scand J Gastroenterol. 1996;31:154-159.

23. Nielsen HW, Tüchsen F, Jensen MV. [Validity of the diagnosis 'essential hypertension' in the National Patient Registry]. Ugeskr Laeger. 1996;158:163-167. Danish.

24. Krarup L-H, Boysen G, Janjua H, et al. Validity of stroke diagnoses in a National Register of Patients. Neuroepidemiology. 2007;28:150-154.

25. Pedersen M, Klarlund M, Jacobsen S, et al. Validity of rheumatoid arthritis diagnoses in the Danish National Patient Registry. Eur $J$ Epidemiol. 2004;19:1097-1103.

26. Lassen A, Hallas J, de Muckadell OBS. Complicated and uncomplicated peptic ulcers in a Danish County 1993-2002: a population-based cohort study. Am J Gastroenterol. 2006;101:945-953.

27. Nickelsen TN. [Data validity and coverage in the Danish National Health Registry. A literature review]. Ugeskr Laeger. 2002;164:33-37. Danish.

28. Vestberg K, Thulstrup AM, Sørensen HT, et al. Data quality of administratively collected hospital discharge data for liver cirrhosis epidemiology. J Med Syst. 1997;21:11-20.
Clinical Epidemiology

\section{Publish your work in this journal}

Clinical Epidemiology is an international, peer-reviewed, open access journal focusing on disease and drug epidemiology, identification of risk factors and screening procedures to develop optimal preventative initiatives and programs. Specific topics include: diagnosis, prognosis, treatment, screening, prevention, risk factor modification, systematic

\section{Dovepress}

reviews, risk \& safety of medical interventions, epidemiology \& biostatical methods, evaluation of guidelines, translational medicine, health policies \& economic evaluations. The manuscript management system is completely online and includes a very quick and fair peer-review system, which is all easy to use. 